\title{
PROCESSAMENTO E IMAGEAMENTO DE DADOS SÍSMICOS MARINHOS COMPLEXOS
}

Thaina Karoline Canté Silva*, Universidade Federal do Oeste do Pará - UFOPA

Erverlon Bruno da Paixão Chaves, Universidade Federal do Oeste do Pará - UFOPA

Beatriz Teixeira Guimarães, Universidade Federal do Oeste do Pará - UFOPA

Raimundo Nonato Colares Carneiro, Universidade Federal do Oeste do Pará - UFOPA

Copyright 2019, SBGf - Sociedade Brasileira de Geofísica

This paper was prepared for presentation during the $16^{\text {th }}$ International Congress of the Brazilian Geophysical Society held in Rio de Janeiro, Brazil, 19-22 August 2019.

Contents of this paper were reviewed by the Technical Committee of the $16^{\text {th }}$ International Congress of the Brazilian Geophysical Society and do not necessarily represent any position of the SBGf, its officers or members. Electronic reproduction or storage of any part of this paper for commercial purposes without the written consent of the Brazilian Geophysical Society is prohibited.

\section{Abstract}

This Work Course Conclusion (TCC) aimed processing of marine seismic data using the data PLUTO 1.5 a given elastic 2D seismic established in November 2000, to simulate properties of propagation of elastic waves in domes saline the Gulf of Mexico. The model has a horizontal length of $32 \mathrm{~km}$ and vertical $9.14 \mathrm{~km}$. Processing and imaging of the data is divided into two stages: pre-processing and processing in a flowchart shown here. The procedures respect are the first step of preprocessing (1) $f$ bandpass filtering trapezoidal, (2) $f-k$ filtering trapezoidal bandpass (3) Correction spherical divergence. The data processing procedures are used for preprocessing the output files and followed the following steps: (1) velocity analysis; (2) MNO correction; (3) Stacking; (4) Kirchhoff migration post stack time; (5) Migration Kirchhoff post stacking depth. The above processing steps were carried out using the system free Seismic Un * $\mathrm{X}$, developed by Central Wave Processing (CWP) of the Colorado School of Mines.

\section{Introdução}

A sísmica de reflexão é o ramo da Geofísica que busca por informações da estrutura interna da Terra a partir da propagação de ondas sísmicas em seu interior. O processo de aquisição de dados se inicia a partir da excitação de uma fonte emissora de ondas mecânicas em ambientes terrestres ou marinhos. Ao se propagar, a onda sísmica sofre sucessivas reflexões e transmissões nas diferentes interfaces que separam meios com propriedades físicas distintas, como velocidade e densidade. Naturalmente, estes eventos produzem sinais de reflexão desejados e não desejados, sendo necessário o aumento da razão do sinal dos sinais desejados e a atenuação da energia dos sinais indesejados.

Para se realizar uma aquisição sísmica, deve-se pensar no arranjo espacial no qual as fontes e receptores das ondas estão dispostos, existindo diferentes configurações. Por exemplo, pode-se realizar um levantamento na configuração Fonte Comum(FC) (Figura 1).

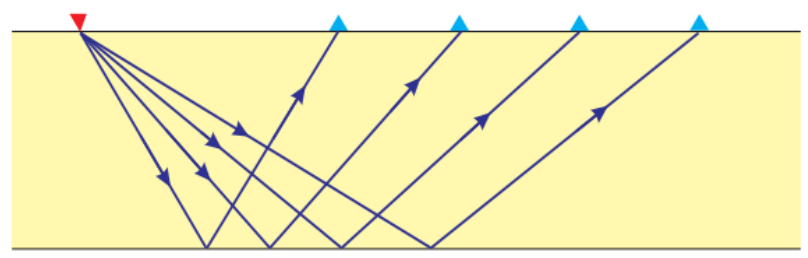

Figura 1. Arranjo sísmico na configuração Fonte Comum (FC). $\nabla$ é a Fonte, definida pela coordenada $X_{s}$ e $\Delta$ são os receptores, definidos por suas coordenadas $X_{g}$.

$\mathrm{Na}$ configuração $\mathrm{FC}$, todos os raios são originados da mesma fonte, refletindo na interface que separa meios com propriedades físicas distintas e retornando à superfície, sendo então captados pelos sensores.

Outra configuração possível é denominada Afastamento Comum (AC). Esta é construída com todas as fontes e receptores com mesmo afastamento. (Figura 1.1).

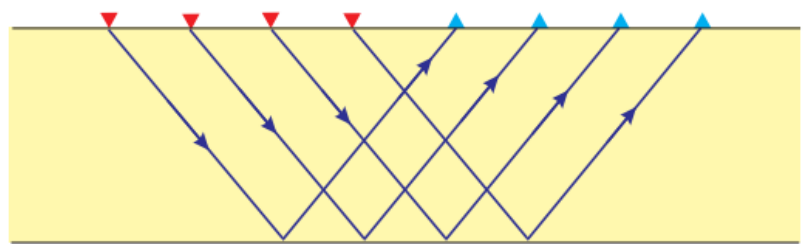

Figura 1.1. Arranjo sísmico na configuração Afastamento Comum (AC). $\nabla$ é a Fonte, definida pela coordenada $X_{s} e$ $\Delta$ são os receptores, definidos por suas coordenadas $X_{g}$.

Uma configuração AC especial é chamada de Afastamento Nulo (AN). Nesta configuração o afastamento do par fonte-receptor é zero, ou seja, a fonte e o receptor estão na mesma posição (Figura 1.2).

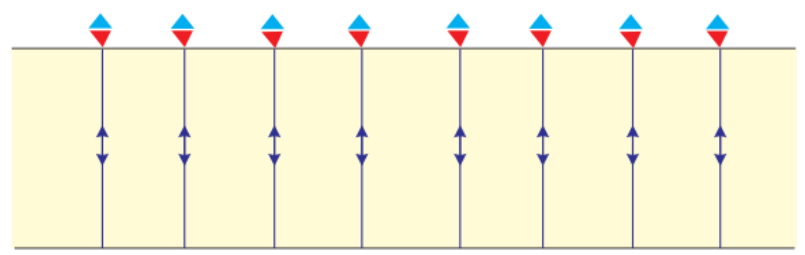

Figura 1.2. Arranjo sísmico na configuração Afastamento Nulo (AN). $\nabla$ é a Fonte, definida pela coordenada $X_{s}$ e $\Delta$ são os receptores, definidos por suas coordenadas $X_{g}$.

Apesar de sua grande importância no processamento sísmico (conforme veremos mais adiante), a configuração AN não pode ser realizada nas aquisições sísmicas, pelo 
fato de que, quando detonada, a fonte destruiria o receptor.

Outra configuração importante é denominada Ponto Médio Comum (PMC), na qual todos os pares fontereceptor possuem o mesmo ponto médio comum (Figura 1.3).

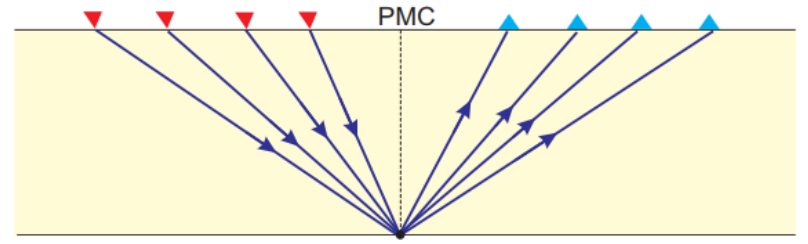

Figura 1.3. Arranjo sísmico na configuração Ponto Médio Comum (PMC). $\nabla$ é a Fonte, definida pela coordenada $X_{s}$ e $\Delta$ são os receptores, definidos por suas coordenadas $X_{g}$.

Após a organização da geometria, as fontes são acionadas e as ondas mecânicas se propagam para a subsuperfície, sendo captadas pelos receptores. O resultado da captação das ondas sísmicas pelos receptores é mostrado graficamente através de traços sísmicos, conforme mostrado na Figura 1.4.

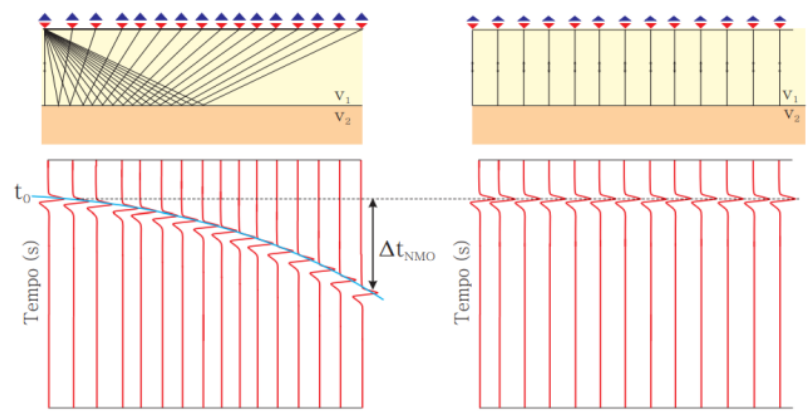

Figura 1.4. Obtenção dos sismogramas resultantes das reflexões das ondas sísmicas.

Para iniciar as etapas de processamento sísmico observou-se a que mostra uma seção offset mínimo do dado Timodel II (Figura. 2), onde observa-se uma baixa resolução sinal/ruído, que deve ser melhorada.

O estudo teve como objetivo realizar o processamento sísmico, explicando suas etapas teóricas e práticas e obter a seção simulada de AN mais limpa possível de ruído coerente e aleatório.
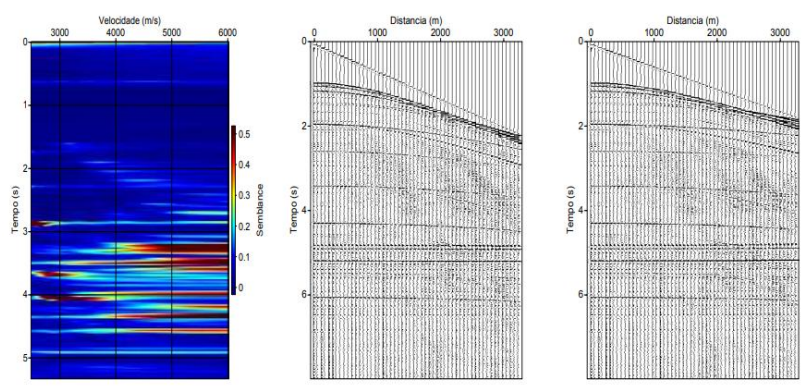

Figure 1.5. CMP 100: mapa semblance (à esquerda); antes da correção NMO (meio) e após a correção NMO (à direita).

\section{Metodologia}

Para chegar ao resultado desejado, ou seja, explicar as etapas de processamento sísmico e obter a seção simulada AN mais limpa possível de ruído coerente aleatório, foram observados dados sísmicos marinhos (Fig.2) usando os dados TIMODEL II, dado sísmico 2D elástico criado para simular propriedades da propagação de ondas elásticas em domos salinos. O modelo tem extensão horizontal de $45 \mathrm{~km}$ e vertical de $8 \mathrm{~km}$.

Para isso, foi utilizado o pacote sísmico seismic $u n^{*} x$ da Center for Wave Phenomena (CWP) da Colorado School of Mines (COHEN; STOCKWELL,2005) e levou-se em considerações as seguintes etapas de tratamento: Préprocessamento e Processamento: Filtragem $f$ passabanda trapezoidal; Filtragem f-k passa-banda trapezoidal; Correção de divergência esférica.Os procedimentos do processamento dos dados se utilizou dos arquivos de saída do pré-processamento e seguiu as seguintes etapas que são: Análise de velocidade; Correção MNO; Empilhamento; Migração Kirchhoffpós empilhamento no tempo; Migração Kirchhoff pós empilhamento na profundidade.

\section{Resultados}

A estimativa da distribuição de velocidade na seção sísmica usa o dado organizado em família CMP, usando a medida semblance, faz a correção $\mathrm{NMO}$, realiza o empilhamento e pode ser usada na migração. A estimativa de velocidade foi acoplada ao mapa semblance (Figura 1.5) observando que a seção offset mínimo do dado Timodel obteve sensível melhora na razão sinal/ruído e melhor visualização das múltiplas contidas no dado. Após a análise de velocidade foi efetuado o empilhamento para cada família CMP, onde observou-se características típicas de eventos de difração e das principais interfaces refletoras, bem como o contorno do assoalho oceânico. Nesta etapa de empilhamento NMO em tempo do dado Timodel II realizada a partir de marcações manuais no mapa semblance nos eventos de reflexão em $30 \mathrm{CMPs}$ de um total de 616 CMPs demonstrou também que a maior parte da informação registrada correspondeu a eventos rasos até a janela de $2.0 \mathrm{~s}$, região em que os eventos refletores possuem boa descontinuidade e, após esta janela os eventos de alta frequência dificultaram a retirada de mais informações do dado.

Na seção migrada Kirchhoff pós empilhamento (Figura 3) no tempo do dado Timodel II sobre a seção empilhada NMO, ultilizando o modelo de velocidade RMS, pôde-se observar o colapso parcial das difrações e a recuperação de vários eventos refletores em grandes profundidades. Contudo, se observam arcos sobre os pontos difratores nas regiões mais profundas da seção. 


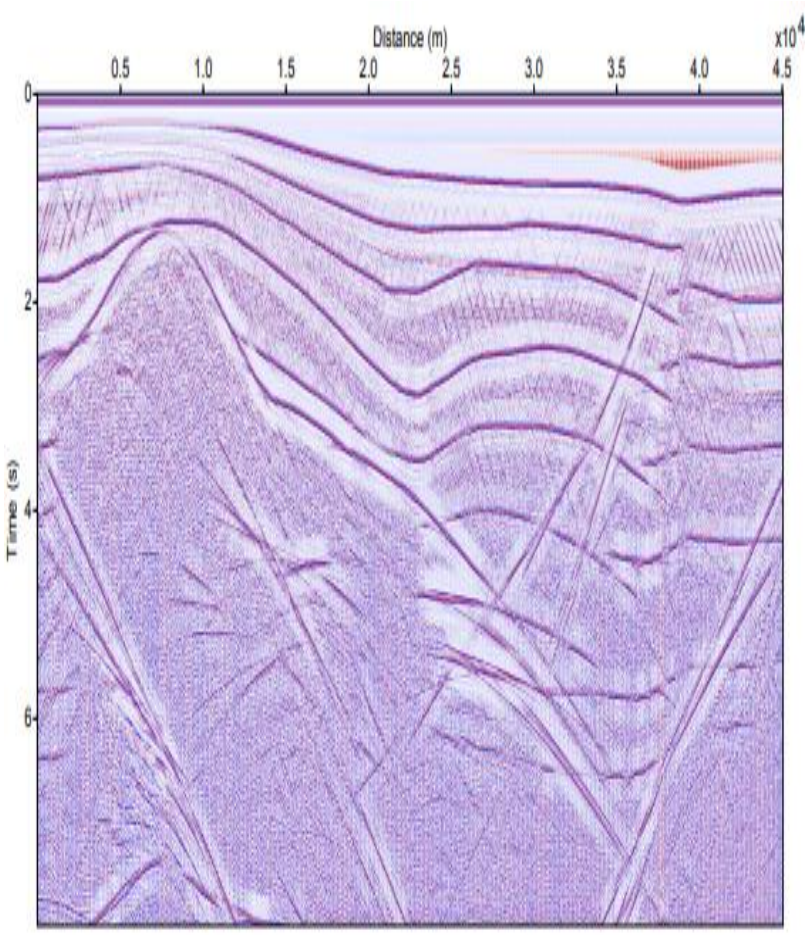

Figure 2. Seção offset mínimo do dado Timodel II antes da correção normal moveout. Obseva-se baixa resolução na razão sinal ruído do dado.

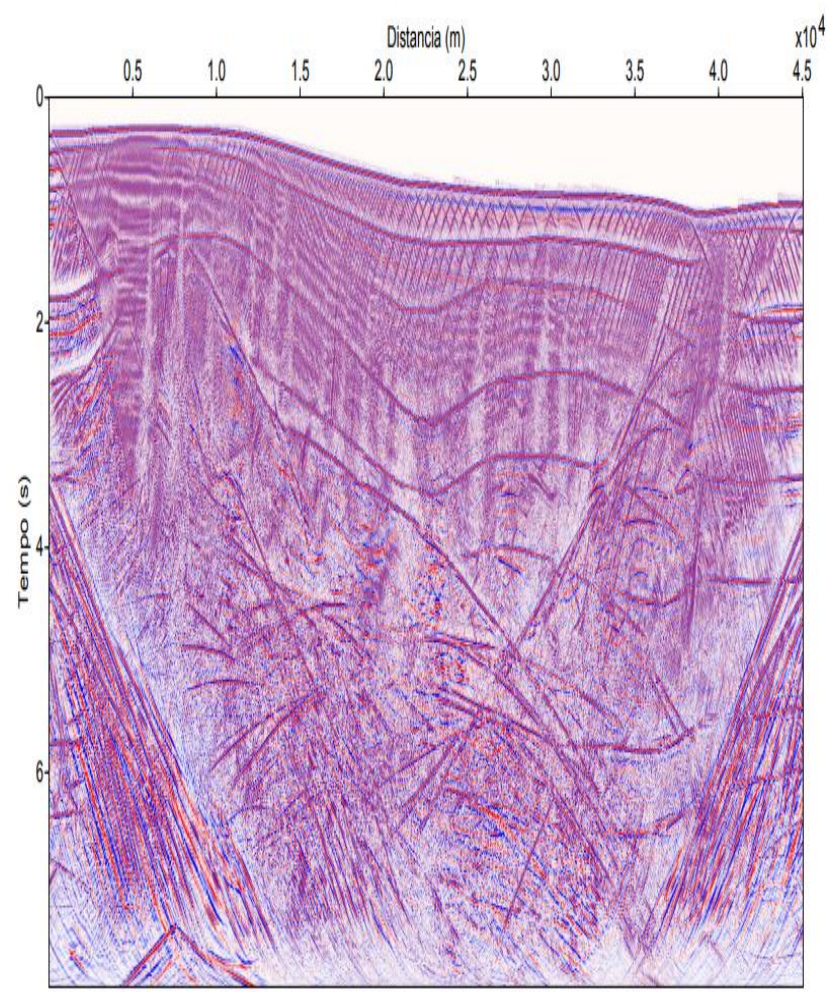

Figure 3. Seção offset mínimo do dado Timodel Il após todas as etapas de Pré-processamento e processamento. Resultado final.

\section{Conclusão}

Após a aplicação da metodologia de correção normalmoveout (NMO) proposta neste estudo no tratamento do conjunto dos dados sísmicos Timodel II através de um fluxo de processamento para aprimorar a relação sinal/ruído deste dado, mostrou que a correção NMO gerou resultado satisfatório, visto à complexidade do mesmo. Portanto, ao finalizar a análise dos resultados, conclui-se que o processamento dos dados proporcionou um aumento significativo na relação sinal/ruído do dado, comprovando a boa performance da metodologia NMO.

Como sugestão para trabalhos futuros, se propõe a aplicação de outras técnicas de deconvolução de múltiplas e de migração pré e pós-empilhamento no tempo e na profundidade baseadas na equação da onda acústica, como as metodologias PSPI (phase-shift plus inter-polation), SS (split-step),RTM (reverse time migration) e FFD (Fourier finite difference), para efeito de comparação com a migração Kirchhoff e aplicação das técnicas CRS e nipto-mográfica, voltado à obtenção de melhores imagens úteis para a interpretação geológica.

\section{Agradecimentos}

A instituição pelo corpo docente e apoio técnico necessário. Agradecemos as pessoas que contribuíram e contribuem na formação de cada dia, em especial ao nosso orientador, Prof. Raimundo Nonato Colares Carneiro por todo o conhecimento repassado e auxilio na elaboração e construção deste trabalho.

\section{Referências}

COHEN, J. K.; STOCKWELL, J. J. W. CWP/SU: Seismic Un*x Release 39 - a free package for seismic research and processing. 1. ed. Colorado School of Mines: Center for Wave Phenomena, 2005.

DIX, C. H. Seismic velocities from surface measurements. Geophysics, Tulsa, OK, v. 20, p. 1662-1672, 1955.

KEAREY MICHAEL BROOKS, I. H. P. Geof'ısica de explora, cªo. Tulsa, OK: Oficina de textos, 2009.

SCHNEIDER, W. A. Integral formulation for migration in two-dimensions and three-dimensions. Geophysics, v. 43, n. 01, p. 49-76, 1978.

TANER, M. T.; KOEHLER, F.; ALHILALI, K. A. Estimation and correction of near-surface anomalies. Geophysics, Tulsa, OK, v. 39, n. 4, p. 441-463, 1974.

YILMAZ, O. Seismic data processing. Tulsa, OK: Society of Exploration Geophysicists, 1987. 